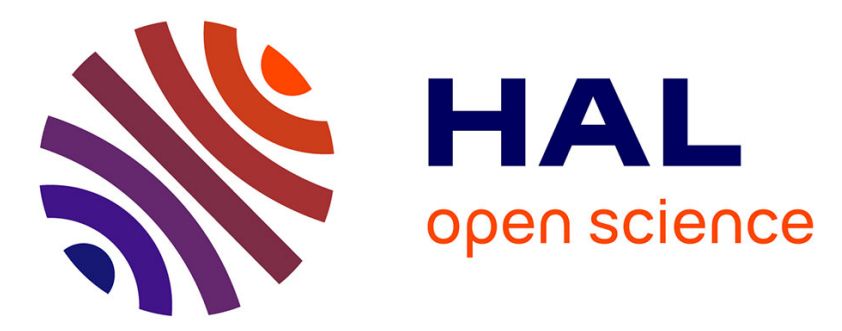

\title{
Creating Local Government Innovation
}

Fredrik Söderström, Ulf Melin

\section{To cite this version:}

Fredrik Söderström, Ulf Melin. Creating Local Government Innovation. 18th International Conference on Electronic Government (EGOV), Sep 2019, San Benedetto del Tronto, Italy. pp.125-138, 10.1007/978-3-030-27325-5_10. hal-02445811

\section{HAL Id: hal-02445811 \\ https://hal.inria.fr/hal-02445811}

Submitted on 20 Jan 2020

HAL is a multi-disciplinary open access archive for the deposit and dissemination of scientific research documents, whether they are published or not. The documents may come from teaching and research institutions in France or abroad, or from public or private research centers.
L'archive ouverte pluridisciplinaire HAL, est destinée au dépôt et à la diffusion de documents scientifiques de niveau recherche, publiés ou non, émanant des établissements d'enseignement et de recherche français ou étrangers, des laboratoires publics ou privés. 


\title{
Creating Local Government Innovation - Lessons Learned From An Institutional Theory Perspective
}

\author{
Fredrik Söderström $\square^{1[0000-0002-2422-0900]}$ and Ulf Melin ${ }^{1[0000-0002-2784-863 X]}$ \\ ${ }^{1}$ Linköping University, SE-581 83 Linköping, Sweden \\ \{fredrik.soderstrom, ulf.melin\}@liu.se
}

\begin{abstract}
The public sector is facing an equation that cannot be solved by continuing doing business as usual. External demands of availability, quality and resilience of services, as well as internal demands of resource efficiency, are putting pressure on the public sector to seek for innovation. In this study, we focus on local government innovation where high expectations are set on better utilisation of employees' creativity and innovative capacity. Based on a qualitative case study of an innovation programme in a Swedish local government organisation, this study applies institutional theory as a theoretical lens to further investigate and analyse the relationship between formal and informal structures of local government innovation. The institutional structures related to norms and values, legitimacy and decoupling as well as digital artefacts as institutional carriers are discussed. Implications for practice show that formal structures, processes and digital artefacts to support local government innovation are important in this work. However, to achieve government innovation, equal attention should also be given to informal institutional structures of innovation. For research, this implies that government innovation studies can benefit from an institutional theory perspective to develop a better understanding of how informal structures affect related processes. We conclude by arguing that the needed change towards the innovative bureaucracy is a transformative innovation in itself that needs to be acknowledged.
\end{abstract}

Keywords: Local Government Innovation, Public Sector Innovation, Institutional Theory, Public Sector ICT, Digitalisation.

\section{$1 \quad$ Introduction}

A general perception, in research as well as practice, is that public sector organisations face significant challenges in the present and future. These challenges are the result of increasing internal demands, e.g. increased efficiency, as well as external demands on quality, availability and resilience of services. Taking advantage of the internal intellectual capital in order to increase the innovative ability of public sector organisations is seen as a suitable means, or even a must, to aid in meeting current challenges [e.g. 1, 2]. By investigating a local government innovation initiative, this study aims at looking beyond current perspectives in research focusing on formal structures to support and facilitate government innovation. The focused local government innovation programme is the result of current internal and external demands or 
pressures put-on public-sector organisations in Sweden to increase their innovative ability. This ability is related to the creativity of co-workers, hence the aim is to facilitate internal innovation. In previous studies, innovations are described as new ways of structuring and arranging processes and activities in order to achieve significant improvement [e.g. 3]. An innovation always starts with an idea. The idea is the spark that ignites the process of innovation with the goal of implementing innovation into daily operations. However, an idea does not always become an innovation. The innovation process is associated with a significant amount of uncertainty and risk; hence this creates a need for structured and systematic process management [4], but at the same time, uncertainty and risk challenge the planning, control and coordination of innovation activities [5]. The innovation and operations must converge to be successful; the organisation needs to successfully manage "action knowledge and thinking knowledge" [6]. However, government innovation tends to be problematic, as confirmed by research and shown in this study.

Existing processes and structures are potentially challenged [7], and public organisations, as examples of bureaucracies, often have a "zero-error culture" [8]. Moreover, there are several contradictions regarding local government innovation. For example, municipalities have the mission to be politically driven tax-funded service providers. They are local bureaucracies, albeit with a positive connotation. One can, therefore, question whether local government innovation is in line with this mission and the public interest? What creates the acceptance and legitimacy for local government to spend resources on initiatives associated with significant risks, uncertainty and potential failure? In contrast to research and practice focusing on formal and rational ways of increasing government innovation, equal attention must be given to the social, behavioural and value-based prerequisites and capacity to innovate; i.e. the "actual patterns of behaviour and work routines" [9]. These informal structures are manifested in shared behaviour, culture, norms and values and have a potential impact in this area.

This study applies institutional theory ${ }^{1}$ as a theoretical lens. As a point of departure, we see local government innovation as a collective behaviour that needs to be socially established [10], i.e. institutionalised, across the organisation. Institutional theory provides opportunities to better understand organisational irrationalities [11] as seen in this context as well as a way to relate formal and informal structures in local government innovation. Moreover, digital artefacts have an important role in facilitating government innovation. These artefacts can act as carriers of institutional ideas [12], i.e. government innovation as a desired collective behaviour, across organisational boundaries. This study addresses the following research questions: RQ-1) What are the results and effects of a local government innovation programme? RQ-2) What lessons can be learned from applying institutional theory on local government innovation? The paper structure is as follows: Section two covers related research in the areas of ideas and innovations, government innovation as well the institutional perspective. Section three presents the case study and the research approach followed by empirical findings from the case study presented in section four. The result of apply-

${ }^{1}$ This should be considered being a new or neo-institutional perspective (see e.g. Scott, 2014). 
ing an institutional perspective is discussed in section five, and the paper concludes with implications for research and practice as well as suggestions for further research in section six.

\section{$2 \quad$ Related Research}

\subsection{Ideas and Innovations}

There is some disagreement among researchers about the meaning of the concepts of ideas and innovations. However, there is a shared consensus that these two concepts are significantly different. Every innovation starts with an idea, but innovation also requires management and coordination to bring potential benefits [13]. Innovations depend on ideas but far from all ideas become innovations. The stage of idea generation can be seen as trivial while there are significant challenges during the realisation of ideas into innovations [13]. This study is based on the following definition: "Successful innovation is the creation and implementation of new processes, products, services and methods of delivery which result in significant improvements in outcomes efficiency, effectiveness or quality" [3]. The idea is the critical prerequisite, the spark, initiating the process of realising the idea into an innovation. Innovations are often described as processes [14], and one must also bear in mind that innovation processes do not always result in successful innovations [13]. Transferring an idea from the intellectual to conceptual level further on to the operational level is always related to significant risks. Systematic and structured innovation processes have a positive impact on realising ideas into innovations [4]. It is essential to identify and successfully manage different stages or phases in innovation work [15]. Innovations are categorised as incremental, radical or transformative [3]. While incremental innovations result in minor changes in existing activities, radical innovations lead to significant improvements while maintaining existing dynamics between actors (ibid.). Transformative innovations fundamentally change a sector's foundation and give rise to new organisational forms [3].

\subsection{Government Innovation}

Innovation has a critical strategic value for public management [16]. Government organisations face unprecedented challenges, and traditional established approaches will not be enough [1]. The processes supporting government innovation cannot be traditional top-down but instead must take advantage of all potential sources of innovation; internal as well as external to the organisation [1]. To be able to gain a positive result from innovation work, public organisations must be exposed, willing and responsive to innovation [17]. Like other organisational changes, there is a need for top-management support to create the legitimacy needed for innovation work across organisations [e.g. 7]. Government innovation addresses and challenges traditional structures and operations. It becomes essential to acknowledge the need for minimising the potential resistance to new and innovative ways of structuring work and performing activities [17]. Moreover, government innovation always occurs at the expense of regular activities [17]. Limited resources and strained operations in contem- 
porary public sector organisations can, therefore, cause problems [17]. Government innovation differs from innovation work in the private sector. Public organisations are tax-financed and governed by laws and regulations; organisations must thereby fund the innovation work themselves instead of bringing in external venture capital [7]. The error margins in the public sector are also different from the private sector. Constant media coverage does not hesitate to make headlines of any failure [7].

Different approaches to tackle current and future societal challenges are put forth. For example, the concept of social innovation focuses on meeting social needs by developing and using new social processes [18]. Another strategy proposed specifically for government innovation is collaborative innovation [e.g. 1, 19, 20]. Collaborative innovation utilises diversity across the organisation while challenging existing organisational boundaries [1]. By opening up the innovation process and integrating different actors, the availability of resources and assets without bureaucratic boundaries become a crucial factor for this approach [19]. As a networkbased approach, the origin of collaborative innovation is linked to historical research on governance networks and network governance [8]. Since the research field of government innovation is a relatively new subfield, researchers acknowledge a need for more studies [e.g. 8, 21]. Accordingly, this study is an answer to this call.

\subsection{Institutions and Institutional Carriers}

The institutional theory perspective emphasises the need for considering informal aspects of organising as well as formal and rational structures and activities [11]. The organisational context is thereby considered being of importance as having a significant influence on decisions and activities [22]. There is a need to acknowledge how different terms and variations in the organisational context affect organisational activities [23]. The focus is put on the tacit, implied or unspoken, for example, in the form of norms, values, beliefs and interpretations [23]. These are socially constructed meanings shared among individuals and transferred over time [9]. Institutions are systems of social control [24] or social structures that restrict and guide behaviour in social arrangements [9]. Studies apply the institutional perspective to analyse either the external, i.e. environment as an institution or the internal, i.e. organisation as an institution [25]. The concept of institutionalisation is a constructionist view addressing institutional elements such as norms and values [25]. Organisational legitimacy is an essential factor that affects and is affected by institutional aspects such as norms and values [26]. Legitimacy is the appropriateness of action in line with existing definitions, beliefs, norms and values [26].

Decoupling is a critical aspect of institutionalisation and refers to the process of the organisation, avoiding integration of formal structures due to, for example, inconsistencies or anomalies [27]. Formal structures are changed only in a ceremonial manner letting organisational units perform their activities as usual [9]. Decoupling results in formal structures not being aligned or coupled with how work is being performed across the organisation. Institutions are also transferred across an organisation by different institutional carriers $[9,12,28]$ such as values and expectations, activities and artefacts [9]. Studies have shown that for example, digital artefacts as carriers are important to consider when investigating the process of institutionalisation [e.g. 29, 
30]. Although institutional theory has received considerable attention in e-government research, the application of this type of sociological perspective in government innovation research is still limited. However, this study is in line with previous research put forth by, for example [5].

\section{$3 \quad$ Research Approach and Case Study}

The presented research is the result of a study conducted at a municipality in 2017 and was initiated in late 2016 when the municipality contacted the authors. The municipality described a desire to evaluate the outcome of the idea and innovation programme, henceforth referred to as the innovation programme. In Sweden, municipalities are politically controlled local government entities governed by the local government act with responsibilities and services in areas such as preschool and education, health and social care, local business, environment and urban planning. The municipality has seven administrations operating the activities in committees' areas of interest and responsibility. The innovation programme was initiated before central guidance, and financial support was offered on a national level to promote this kind of development [e.g. 31, 32, 33]. At the time of this study, the municipality was seen as a forerunner in local government innovation. Although being a single case study, we argue that this case offers an opportunity for knowledge development regarding local government innovation. Conducing a qualitative interpretive case study [e.g. 34, 35] achieving generalisability across empirical settings is not sought. Instead, by applying an analytical perspective, we aim at developing a deeper understanding of local government innovation, which in turn can inform other settings focusing on this phenomenon [c.f. 36].

Mainly based on qualitative data, quantitative data was also used as a complementary source. During the first phase of the study, a web survey was designed and submitted to 40 respondents assigned to roles linked to the innovation programme. The online questionnaire consisted of 13 five-point Likert scale questions supplemented with six open-ended/free text questions. The web survey reached a response rate of 75 per cent. The focus of this survey was to investigate the introduction of the programme, its outcome and current effects on a general organisational as well as operational level. The results were analysed using basic descriptive statistics and integrated into the overall qualitative case study. During the second phase of the study, ten semistructured interviews [e.g. 37] were conducted face-to-face with respondents on different organisational levels across the organisation. Identified by referral sampling [38], all respondents had clear connections to the programme either as department managers, owners/coordinators of related processes or as assigned representatives to support the programme.

Distribution of respondents' roles $^{2}$ : manager (2), idea coach (2), IT strategist ${ }^{3}$ (1), contact person (2), inspirer (3). The aim was to involve employees already involved in the programme to assess and evaluate the results and effects. The interviews were guided by the preliminary result of the web survey and aimed at further investigating

\footnotetext{
${ }^{2}$ Please refer to section 4.1 for a description of roles.

${ }^{3} \mathrm{~A}$ former employee involved in the development of the innovation programme.
} 
ideas and innovations as interpreted and translated among respondents as well as the level of operationalisation of the programme. In parallel with data collection activities, a hermeneutic literature review [39] was performed covering relevant areas of research. Institutional theory and previous research on innovations were used as a guide for further investigations and analysis [35]. A thematic approach was applied iteratively during data analysis allowing for constant focus shifts between empirical data and literature; i.e. a reflexive approach [40]. The analysis was performed on different levels such as individual, group and organisational. Digital artefacts were also handled as a level of analysis. During the case study, the researchers stayed in regular contact with the municipality. Emerging findings and tentative results were discussed in meetings and seminars in order to report work in progress as well as to validate results. The result and implications for practice were reported back in written form to the municipality in October 2017 and therefore also served as a process of validating the results.

\section{Empirical Findings: The Innovation Programme}

\subsection{Formal Structure and Process}

The innovation programme was established in 2015 with the objective to realise at least 100 ideas per year. The aim is to increase the ability to make use of employees' creativity and competence to handle current and future challenges. The programme should also support current initiatives in research and business development through increased cooperation between administrations. Employees are supported during assessment, development and realisation of their ideas. The programme should also facilitate administrations' prioritisation and implementation of proper development efforts. The programme consists of a formal structure and process, a central supporting function (the Idea Sluice) ${ }^{4}$ and a web portal (the Idea Portal). There are defined roles assigned to the programme: (1) the carrier - an employee having an idea, (2) the coaches - central roles responsible for supporting the innovation process and (3) the counsels - which at the administrative level decides whether the idea is to be supported or not. On a general level, the municipality's innovation programme contains a formal innovation process consisting of four main phases as illustrated in Figure 1 below. The first phase of Assessment (1) is performed by the carrier in cooperation with the coach with the aim of concretisation and quality assurance of the idea. The idea is then presented to the council deciding if the idea is to be supported or not. If supported, the second phase of development, test and evaluation (2) can be initiated. The result is presented to the council assessing and evaluating the result. If showing positive realisability, the process can continue into the third phase of expanded pilot testing (3) and the fourth phase of implementation (4).

\footnotetext{
${ }^{4}$ The motive for using this term as a metaphor in this context is based on the purpose of the supporting function resembling a device for facilitating and controlling the flow of ideas within the organisation.
} 


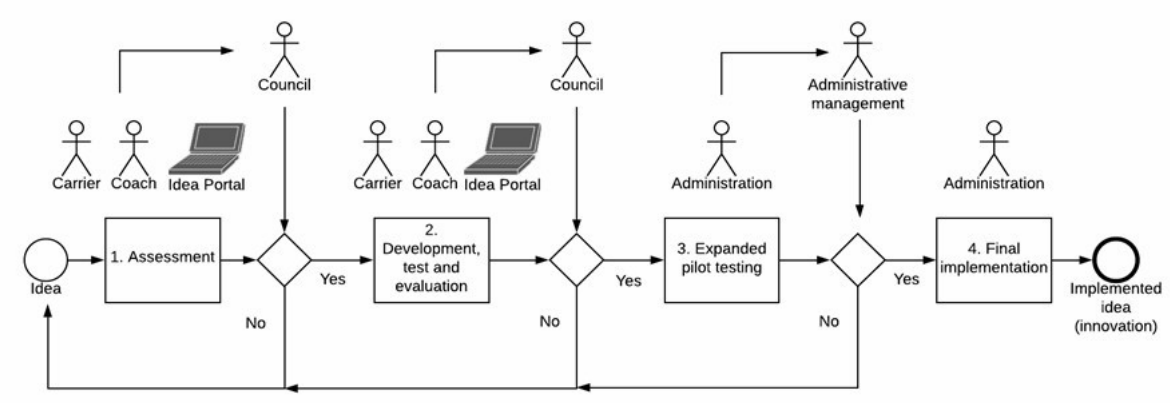

Fig. 1. The formal innovation process

If the idea is dismissed by the council or administration, the carrier can always try to develop further and refine the idea and try to initiate another process cycle. The process is supported by a digital artefact, the Idea Portal, described in the next section. The programme also includes two additional roles not directly involved in the formal innovation process. The contact persons act as local contact points, and the aim of the inspirers is to support and facilitate the innovation programme at the local operational level.

\subsection{The digital artefact: An Idea Web Portal}

The digital artefact, the Idea Portal, is based on a traditional web interface and is accessible via the municipality's Intranet. The portal allows for basic functionality for submitting ideas and keeping information of ideas updated during the phases of the process, e.g. assigning different statuses with progress updates. The assigned status of an idea corresponds to the main phases of the process as previously described (see Figure 1 above). Ideas can also be shown with a status of being cancelled, paused or redirected, i.e. passed on to a specific business area. The carrier can access their own ideas in a personalised view while all employees have access to the overall view of submitted ideas. The portal is mainly used by the coach and carrier during the first two phases, i.e. assessment (1) and development, test and evaluation (2). The Idea Portal is described as a positive incentive, for example, bringing visibility and transparency to the programme (Manager 2, 2017). "I think it is important because it becomes a structure - otherwise it would have been totally invisible. [..] It [the portal] supports legitimacy and understanding." (Inspirer 2, 2017). The part of the organisation affected by the idea and its current status becomes clear (Inspirer 1, 2017).

The Idea Portal has had a positive contribution; however, mostly focused on the initial phase of submitting ideas. This phase now has a much higher level of legitimacy, and the portal, together with assigned roles, has contributed to increased visibility (Contact Person 2, 2017). Instead of using a dedicated system, i.e. innovation management software, the portal is developed based on a traditional case management system (Coach 2, 2017). Respondents thus describe a need to further develop the portal, for example, regarding improved functionality for dialogue, interaction, coopera- 
tion as well as features for evaluating/rating ideas. Hence, the innovation process could potentially make better use of digital channels (Coach 2, 2017).

\subsection{Results and Effects}

The programme is described as having positive effects on a general level. According to one respondent: "This is a municipality where you are serious about the idea work. You really want to take advantage of the employees' creativity." (Inspirer 1, 2017). Respondents also emphasise that government innovation should not compete with regular business development activities but rather complement and handle ideas that cannot be handled by such systems (Coach 2, 2017; Inspirer 1, 2017). However, several challenges are put forth by respondents. The assigned roles work well, but the lack of establishment and top management support affect the programme (Manager 1, 2017; Coach 2, 2017; Inspirer 1, 2017). The central support function is described as an enabler, but limited resources are described as an impeding factor. The function is considered too understaffed (one manager and two coaches) to be able to support the potential amount of ideas (Coach 2, 2017). Although work so far has been positive, one respondent states that this initiative needs more allocated resources (Contact person 1,2017$)$. There is a perceived distance between assigned roles and areas covered by the programme. An example is a distance in time and space between the idea carrier, the support function and the decisions on the administrative management level (see phase 3 and 4 in Figure 1 above).

With too much distance between regular operations and innovation process, the latter risks being perceived as too vague and unclear in turn resulting in a low degree of concern and commitment across the organisation. As a result of this challenge, some administrations have even actively decided not to support the innovation process at all since it is deemed to be redundant (Coach 1, 2017). Respondents, therefore, describe that a potential solution would be to move the central support function closer to local operations. Minimising this gap would facilitate a stronger connection between the innovation programme and regular development activities and in turn, promote a stable and sustainable approach, i.e. integrated with regular business development processes (Manager 2, 2017; Contact Person 2, 2017). In summary, the case study shows that the innovation process, its structure and supporting roles and artefact have had a positive contribution but this initiative has been created and introduced without enough support from regular operations (Manager 1, 2017).

\section{$5 \quad$ Discussion}

\subsection{Norms and Values}

The central concepts, i.e. the idea and the innovation, have not been problematised to any greater extent in the studied organisation during the introduction of the programme. The formal process and structure have been implemented and communicated across the organisation (see Section 4.1). Thus, the municipality has not taken any further notice of how these concepts are interpreted and institutionalised among employees. This motivates a discussion of normative or taken-for-granted assump- 
tions [23] about the programme among respondents. In line with Tolbert and Zucker [41] we argue that the adoption of the programme can be determined by its level of institutionalisation. This social structure aims to guide employees towards being more creative in their workplace for the greater good of local operations as well as the organisation as a whole. To socially establish, i.e. institutionalise, the collective behaviour [10], the programme needs support from employees' norms and values and its perceived legitimacy. Norms and values are often discussed together without separating them. However, it is essential to acknowledge their differences. As conceptions of the desirable or the preferred, values must have standards for assessment and comparison of behaviours and structures [9]. The outcome of the assessment defines if a behaviour should be considered being of value or not.

We consider the official aim of the programme as such a standard, and it is notable that the organisation emphasises how employees' ideas can be used to support internal research and business development through increased cooperation across administrations. This approach can be justified in one sense since employees more easily can relate to ideas than innovations. However, we argue that it poses a significant risk. We find no traces of what is to be desirable or preferred regarding the ability to innovate. According to the programme, ideas are already there ready to be submitted via the Idea Portal for further development. To be able to manage innovations in a systematic and structured way [4], and to reach a higher level of success, the different stages of the innovation process should be handled [15]. We, therefore, argue that the municipality disregards a critical aspect of the innovation process; a work environment that promotes, values and utilises creativity. The working climate must promote creativity since government innovation occurs at the expense of regular activities [17]. Put shortly; the programme neither prescribes that the employee should be creative at the expense of daily work, nor does it say that the employee should take risks or even make any mistakes.

The municipality does not further elaborate on the tradition of government having a potential "zero-error culture" [8] hence being a bureaucracy. According to the programme, a network-based collaborative approach is desirable [8] resembling public sector collaborative innovation [e.g. 1]. Still, to accomplish this, collaboration must be facilitated, and deeply institutionalised organisational boundaries must be challenged and crossed [19]. So again, a non-valued behaviour becomes an assessment standard for other behaviours prescribed in the programme. Based on this discussion, we have identified a recurring pattern of focusing on idea-driven phases of the process as managed by the central support function. There is a lack of normative as well as value-based prescriptions, assessment standards and objectives to cover the later innovation-driven phases of the process.

\section{$5.2 \quad$ Legitimacy and Decoupling}

Legitimacy is "a generalised perception or assumption that the actions of an actor are desirable, proper, or appropriate within some socially constructed system of norms, values, beliefs, and definitions." [26]. The legitimacy of the programme is therefore closely interrelated to its norms and values. The programme consists of a complex, multi-faceted and dynamic set of processes. These processes affect and are affected 
by formal as well as informal structures. The programme can, on a general level, be seen as an example of an attempt to introduce structured and systematic innovation work [4]. The result of the programme is closely related to the level of internal legitimacy gained. The municipality shows the ability and willingness to act and launches an ambitious programme as a response to internal and external pressures and demands. In line with national initiatives [e.g. 31, 32, 33], the aim is to develop and increase local government innovation. Gaining legitimacy by acting upon this pressure is also confirmed by respondents staying favourable of this work. However, respondents report that the programme lacks communicated and sustainable support from top management. Hence, the municipality needs to acknowledge the strategic value of government innovation [16] on the top management level.

While research describes this kind of support as critical for innovation initiatives [7], we also argue that this lack affects employees assigned to the central support function as well as the willingness among administrations to support the system. Respondents show apparent concerns about the support and sustainability of the municipality's innovation programme. We are in full agreement with researchers stating that "ideas are not innovations" [13]. Ideas are a critical part of innovations, but the innovation is so much more! As previously described, the municipality has neither clarified nor problematized these central terms or concepts but instead conflated the concept of ideas in the programme. We argue that this strategy causes fundamental problems and challenges. For example, the case study shows that there are varying interpretations of the aim and purpose of the programme, which in turn directly affect how the programme is perceived based on employees' norms and values. Thus, we argue that this has a direct effect on the programmes perceived legitimacy across the organisation.

As described, decoupling occurs when the integration of formal structures for some reason is avoided; hence, decoupling or coupling instead builds on the notion of the alignment of structures and activities in organisations [27]. We argue that this case shows clear signs of decoupling since a large number of administrations have not integrated the innovation programme into local operations. There can be several reasons for this outcome. For example, respondents report activities prescribed by the programme as conflicting with regular business development efforts [c.f. 27]. Another example is that the aim and purpose of the programme might be seen as ambiguous [27] by employees, especially among those with a lack of knowledge and experience in innovation work. Judging by the result of the case study, the formal structures of the programme works as intended, but in reality, the programme is buffered on the local administration level in turn effectively minimising any conflicts or disputes [27]. We, therefore, argue that the innovation programme, to a large extent, becomes an example of an organisation adopting the required structures but failing in operationalising them, i.e. to have them carried out in daily activities [9].

\subsection{Institutional carriers}

Our findings indicate that carriers of institutional elements are important in local government innovation. This argument is in agreement with researchers stating that carriers are important when considering how institutions change in a way that is divergent 
or convergent [9]. Institutional carriers are not neutral; they affect the message they carry, as well as how this message will be received [9]. We, therefore, argue that these carriers become essential during the process of institutionalisation; what they are, the messages and inscriptions they convey and how actors interpret them. Institutions can, therefore, be transferred across social contexts such as organisations by institutional carriers of several types [28]. Examples of such carriers are relational and symbolic systems, as well as artefacts and activities [9]. The most notable example of a relational carrier, or role system, with defined patterns of interaction [9] in the innovation programme is the structure and process of the programme as a whole with clearly defined related roles on different levels in the organisation. For example, there are clear patterns of interaction in the programme regarding how ideas are assessed on an administrative level by the councils.

The symbolic system acting as a carrier in the programme is made up of the values, expectations and standards [9], in this case, regarding how the municipality will benefit from government innovation. However, the effectiveness and appropriateness of the symbolic system acting as an institutional carrier are also closely related, as previously described, to how the prescribed norms and values affect the organisation and the behaviour of employees, i.e. how these norms and values are institutionalised. The structured phases and tasks included in the formal process (see Figure 1 above) are examples of activities as institutional carriers [9]. Moreover, the aim of the Idea Portal, acting as an artefact as a carrier [9], is to facilitate information and communication primarily during the first two phases of the innovation process.

Based on respondents' reports, the outcome of this artefact as a carrier of information between the Carrier and Coach during the phases of assessment (1) and development, test and evaluation (2) (see Figure 1 above) seems to be positive. Respondents also report that the artefact brings transparency to the process for employees in assigned roles on central as well as administrative and individual levels. However, if the described carriers of the programme are considered in relation to how the institutional idea [12] of the entire process of government innovation as beneficial for the organisation are transferred, we have found that ideas are predominantly put in the foreground. Hence, there is a lack of how the carriers support the institutionalisation of the later phases of the innovation process; i.e. how the idea is further developed into an implemented innovation.

\section{Concluding remarks and future research}

In this study, we focus on the results and effects of a local government innovation programme (RQ-1) and what lessons can be learned from applying institutional theory as a theoretical lens on local government innovation (RQ-2). Addressing the first research question, we conclude that the innovation programme, in the studied organisation, has been a limited success. The municipality has an established a formal structure and process supporting local government innovation. Findings show that the programme has had a positive impact on the opportunity for employees to submit ideas and receive support during initial development and evaluation. However, several shortcomings and challenges have also been identified regarding insufficient 
support, unclear responsibilities, lack of resources and distance in time and space all negatively affecting the programme (see Section 4.3). Addressing the second research question, themes were identified and discussed based on institutional theory. Findings from this analysis show limitation and fragmentation in informal systems and structures supporting the programme (see Section 5.1) as well as insufficient legitimacy and decoupling of the innovation programme from local operations (see Section 5.2). As a result of a limited process view, the Idea Portal, acting as an institutional carrier, fails to support operationalisation and institutionalisation of the innovation process as a whole (see Section 5.3).

As a general conclusion, we, therefore, argue that this study shows that formal and informal structures are equally important in the context of government innovation; government innovation needs to be operationalised as well as institutionalised. Although the innovation programme seems to be a coherent and adequate approach, this study reveals a recurring limited focus on the idea-driven phases of government innovation. This results in a significant lack of how the institutionalisation of the programme is supported; a lesson that goes beyond the studied case. Implications for research suggest a need for supplementing systematic and structured approaches on government innovation [4] with studies focusing on the institutionalisation of government innovation. In government innovation research, there seems to be a tendency to focus on how to encourage and support innovation from a management perspective [e.g. 1, 16, 17]. However, as Demircioglu [21] points out, there is a need for research on employees' attitudes and behaviour in relation to government innovation. In line with this call and based on this study, we put forth the importance of investigating how institutions, as structures of social control [e.g. 9, 24], guide or restrict government innovation. The institutional theory perspective brings a needed constructive potential to reveal the informal structures surrounding and affecting government innovation.

Implications for practice emphasise the importance of acknowledging government innovation as a fundamental government transformation or shift in paradigm across the public sector. In government innovation programmes there is a need to expand the perspective also to include conditions such as how to cultivate innovation culture in public sector organisations and the importance of not only focus on the outcomes regarding ideas and innovations. For example, the conditions for employees also need to facilitate and support creativity; thus, support can be in the form of facilitating creative environments as well as by increasing employees' margin of error. We argue that it becomes crucial to acknowledge local government innovation as a transformative innovation [3] in itself with a potential to fundamentally transform public sector organisations. One limitation in this study is the focus on one local government organisation, in a particular national setting. However, the patterns and results presented above can be linked to previous research and have an analytical generalisability. Although, there is room for expanding future research into new empirical settings and also to compare with other government organisations, on regional, and national level to contrast and to de- and re-contextualise empirical data and findings. 


\section{References}

1. Eggers, W.D., Singh, S.K.: The Public Innovator's Playbook: Nurturing bold ideas in government. Ash Institute, Harvard Kennedy School (2009)

2. OECD: Embracing Innovation in Government - Global Trends 2018. (2018)

3. Mulgan, G., Albury, D.: Innovation in the public sector. Strategy Unit, Cabinet Office 1-40 (2003)

4. Anthony, S.D., Johnson, M.W., Sinfield, J.V., Altman, E.J.: The Innovator's Guide to Growth. pp. 353-379. Harvard Business Press (2008)

5. Van Assche, K., Beunen, R., Lata, I.B., Duineveld, M.: Innovation in Governance. Evolutionary Governance Theory, pp. 313-325. Springer (2015)

6. Frankelius, P.: Questioning two myths in innovation literature. The Journal of High Technology Management Research 20, 40-51 (2009)

7. Borins, S.: Encouraging innovation in the public sector. Journal of intellectual capital 2, 310-319 (2001)

8. Sørensen, E., Torfing, J.: Enhancing collaborative innovation in the public sector. Administration \& Society 43, 842-868 (2011)

9. Scott, W.R.: Institutions and organizations. Sage Publications Inc., Los Angeles, London, New Delhi, Singapore, Washington DC (2014)

10.Hughes, E.C.: The ecological aspect of institutions. American Sociological Review 1, 180189 (1936)

11.Avgerou, C.: IT and organizational change: an institutionalist perspective. Information Technology \& People 13, 234-262 (2000)

12.Scott, W.R.: Institutional carriers: reviewing modes of transporting ideas over time and space and considering their consequences. Industrial and corporate change 12, 879-894 (2003)

13.Kastelle, T., Steen, J.: Ideas are not innovations. Prometheus 29, 199-205 (2011)

14.Van de Ven, A.H., Polley, D., Garud, R.: The innovation journey. Oxford University Press, USA (2008)

15.West, M.A., Sacramento, C.A., Fay, D.: Creativity and innovation implementation in work groups: The paradoxical role of demands. Creativity and innovation in organizational teams 137-159 (2006)

16.Moore, M.H.: Break-through innovations and continuous improvement: Two different models of innovative processes in the public sector. Public Money and Management 25, 43-50 (2005)

17.Stewart-Weeks, M., Kastelle, T.: Innovation in the public sector. Australian Journal of Public Administration 74, 63-72 (2015)

18.Grimm, R., Fox, C., Baines, S., Albertson, K.: Social innovation, an answer to contemporary societal challenges? Locating the concept in theory and practice. Innovation: The European Journal of Social Science Research 26, 436-455 (2013)

19.Bommert, B.: Collaborative innovation in the public sector. International public management review 11, 15-33 (2010)

20.Nambisan, S.: Transforming government through collaborative innovation. IBM Center for the Business of Government Washington, DC (2008)

21.Demircioglu, M.A.: Reinventing the Wheel? Public Sector Innovation in the Age of Governance. Wiley Online Library (2017) 
22.Bowring, M.A.: De/constructing theory A look at the institutional theory that positivism built. Journal of Management inquiry 9, 258-270 (2000)

23.Barley, S.R., Tolbert, P.S.: Institutionalization and structuration: Studying the links between action and institution. Organization studies 18, 93-117 (1997)

24.Berger, P.L., Luckmann, T.: The social construction of reality - A treatise in the sociology of knowledge. Anchor Books, Random House Inc., New York (1967)

25.Zucker, L.G.: Institutional theories of organization. Annual review of sociology 13, 443-464 (1987)

26.Suchman, M.C.: Managing legitimacy: Strategic and institutional approaches. Acad. Manage. Rev. 20, 571-610 (1995)

27.Meyer, J.W., Rowan, B.: Institutionalized organizations: Formal structure as myth and ceremony. American journal of sociology 83, 340-363 (1977)

28.Jepperson, R.L.: Institutions, institutional effects, and institutionalism. The new institutionalism in organizational analysis 6, 143-163 (1991)

29.Melin, U., Axelsson, K., Löfstedt, T.: Understanding an Integrated Management System in a Government Agency-Focusing Institutional Carriers. In: International Conference on Electronic Government, pp. 15-28. Springer, (2018)

30.Gosain, S.: Enterprise information systems as objects and carriers of institutional forces: the new iron cage? Journal of the Association for Information Systems 5, 6 (2004)

31.Vinnova SKL: Överenskommelse: Stärkt innovationsförmåga i offentlig verksamhet 20152017. Vinnova SKL (2015)

32.Vinnova SKL: Reviderad sammanfattning av arbetsprogram - Stärkt innovationsförmåga i offentlig verksamhet 2015-2017. Vinnova SKL (2016)

33.Vinnova: Utlysning: Idéslussar i kommuner - Utvecklingsprojekt 2016. Vinnova (2016)

34.Myers, M.D.: Qualitative Research in Business \& Management. SAGE Publications, London (2009)

35.Walsham, G.: Interpretive case studies in IS research: nature and method. European Journal of information systems 4, 74-81 (1995)

36.Orlikowski, W.J., Baroudi, J.J.: Studying information technology in organizations: Research approaches and assumptions. Information systems research 2, 1-28 (1991)

37.Myers, M.D., Newman, M.: The qualitative interview in IS research: Examining the craft. Information and Organization 17, 2-26 (2007)

38.Biernacki, P., Waldorf, D.: Snowball sampling - problems and techniques of chain referral sampling. Sociological Methods \& Research 10, 141-163 (1981)

39.Boell, S.K., Cecez-Kecmanovic, D.: A hermeneutic approach for conducting literature reviews and literature searches. Communications of the Association for Information Systems 34, 257-286 (2014)

40.Krippendorff, K.: Content analysis: An introduction to its methodology. SAGE Publications, Thousand Oaks (2004)

41.Tolbert, P.S., Zucker, L.G.: Institutional sources of change in the formal structure of organizations: The diffusion of civil service reform, 1880-1935. Administrative science quarterly 28, 22-39 (1983) 